\title{
UV Illumination Room-Temperature ZnO Nanoparticle Ethanol Gas Sensors
}

\author{
Sheng-Po Chang and Kuan-Yu Chen \\ Institute of Microelectronics and Department of Electrical Engineering, Center for Micro/Nano Science and Technology, \\ Advanced Optoelectronic Technology Center, National Cheng Kung University, Tainan 70101, Taiwan \\ Correspondence should be addressed to Sheng-Po Chang, changsp@mail.ncku.edu.tw
}

Received 10 January 2012; Accepted 9 February 2012

Academic Editors: C. S. Casari, C. Li, and W. Lu

Copyright ( $\odot 2012$ S.-P. Chang and K.-Y. Chen. This is an open access article distributed under the Creative Commons Attribution License, which permits unrestricted use, distribution, and reproduction in any medium, provided the original work is properly cited.

Zinc oxide $(\mathrm{ZnO})$ nanoparticle gas sensor was formed by spin coating. We annealed the film at 400, 600, and $800^{\circ} \mathrm{C}$ for 1 hour in air to make gas sensor. The responses of gas sensor to ethanol with UV light illumination were investigated. It could be observed that the $\mathrm{ZnO}$ nanoparticle film annealing at $800^{\circ} \mathrm{C}$ has the highest sensitivity. It can be attributed to the defects of $\mathrm{ZnO}$ nanoparticle film annealing at $800^{\circ} \mathrm{C}$ much more than other annealing temperatures. The study shows that the $\mathrm{ZnO}$ nanoparticles have potential applications as RT ethanol sensors.

\section{Introduction}

Wide bandgap one-dimensional (1D) semiconductor nanostructures such as nanowires [1-6] or nanotubes will become the next-generation devices. With large surface-to-volume ratio and tunable feature size, semiconductor with nanocrystals and nanowires have received people's attention [7-11]. $\mathrm{ZnO}$ (Zinc Oxide) is now a widely used material as photodetector and gas sensor, since it has direct bandgap and special material properties $[12,13]$. Being a promising material for photoelectric device, $\mathrm{ZnO}$ still faces many problems such as high operating temperature and poor sensitivity which might limit its applications. Many solutions have been made to solve these problems, such as the doping of transition elements $[14,15]$ and noble metals [16] or the irradiation of ultraviolet light. Solid-state gas sensors are important in environmental monitoring, chemical process control, and personal safety. Semiconducting metal oxide sensors have been widely studied because of their small dimensions, low cost, and high compatibility with microelectronics. $\mathrm{ZnO}$ gas sensors of various forms, such as thick films [17], thin films [18], heterojunctions [19], nanoparticles [20], and nanotubes [21], have all been demonstrated. The oxygen-related gas-sensing mechanism involves the absorption of oxygen molecules on the oxide surface to generate chemisorbed oxygen species $\left(\mathrm{O}_{2}{ }^{-}, \mathrm{O}^{2-}, \mathrm{O}^{-}\right)$by capturing electrons from the conductance band, making the oxide surface highly resistive. The oxide is exposed to the traces of the introduced reductive gas. In reacting with the oxygen species at the oxide surface, the reductive gas reduces the concentration of oxygen species at this surface and thereby increases the electron concentration [22]. Therefore, 1D ZnO nanotubes should be able to provide large sensitivity because of their large length-to-diameter ratio and surface-to volume ratio. To address the problem of sensor stability, some of the techniques that have been used in the recent past are doping the metal oxides with additives, applying high electric field across the sensor terminals, or illuminating the sensor with UV radiation. Among these, UV illumination of metal oxides, such as $\mathrm{ZnO}$, is the most studied and promising method to achieve room-temperature sensitivity. In this paper, the well-dispersed nanoscale $\mathrm{ZnO}$ suspensions were fabricated by a ball milling equipment. Details of the growth of $\mathrm{ZnO}$ nanoparticles and the properties of the fabricated ethanol sensor are also discussed. This gas sensor device would combine with UV light to sense ethanol gas. The sensitivity $(S)$ is defined as $S=R_{\text {gas }} / R_{\text {ill }}$, where $R_{\text {gas }}$ is sensor's resistance after reaching a steady state when sensing the 


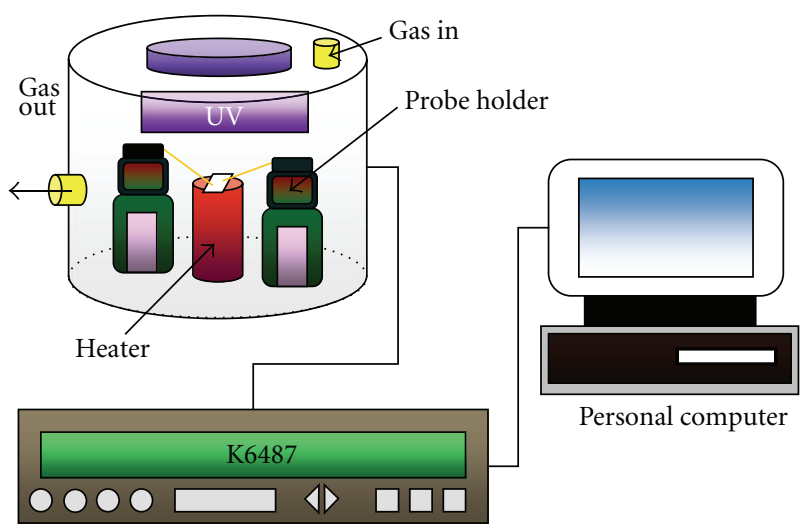

FIgURE 1: The structure of gas sensor measurement.

reducing gas, and $R_{\mathrm{ill}}$ is sensor's resistance with UV light illumination. All experiments in this paper were conducted at room temperature and under UV light illumination.

\section{Experiment}

We formed the thin film with $\mathrm{ZnO}$ nanoparticle by pulverized process. First, $\mathrm{ZnO}$ powder was mixed with adequate amount of organic additives, poly acrylic acid (PAA) (dispersant), polyvinyl alcohol (PVA) (binder), and octanol (antifoaming agent) in aqueous solution. The proper amount of tetramethylammonium hydroxide (TMAH) was added under magnetic stirring. Moreover, the slurry was transferred into the ball milling equipment with $0.1 \mathrm{~mm}$ zirconia beads. The well-dispersed nanoscale $\mathrm{ZnO}$ suspensions were fabricated by a ball milling equipment (JBM-B035, Just Nanotech Co., Taiwan). The milling conditions were set on $3500 \mathrm{rpm}$ and $24 \mathrm{hrs}$. The $\mathrm{ZnO}$ suspension was obtained after filtration process. Then the prepared $\mathrm{ZnO}$ nanoparticles were coated on the $\mathrm{Al}_{2} \mathrm{O}_{3}$ substrate by spin coating technique. First, the $\mathrm{Al}_{2} \mathrm{O}_{3}$ substrate was fixed on the supporting disk of a spin coater (Cee 200, Brewer Science, USA), and adequate amount of $\mathrm{ZnO}$ suspension was dripped onto the substrate. The spin coating conditions of spinning speed and time were set to be $3200 \mathrm{rpm}$ and $10 \mathrm{~s}$, respectively. The coated film of $\mathrm{ZnO}$ nanoparticles was dried at $60^{\circ} \mathrm{C}$ in an oven. The thickness of electrolyte film can be easily controlled by the cycle number of coating. Finally, the baked film and substrate were annealed at 400,600 , and $800^{\circ} \mathrm{C}$ for $1 \mathrm{~h}$ in air. The thickness of $\mathrm{ZnO}$ nanoparticle film was about $1.2 \mu \mathrm{m}$. We measured the electrical (current voltage) properties of the device by HP-4156C semiconductor parameter analyzer. During photocurrent measurement, a 150 watt water-cooled deuterium $\left(\mathrm{D}_{2}\right)$ lamp (HAMAMATSU L1835) was used as the excitation source. We used ethanol as reducing gas when conducting gas-sensing experiment. The schematic diagram of the gas-sensing measurement system is shown in Figure 1. The cylinder-shaped heater and the probe holders were put in a chamber. There is a UV light tube on the top of the chamber. The sample was connected to the probes. When starting to measure the gas sensitivity, we introduced flesh air and reducing gas into the chamber.
The chamber was connected to Keithley 6487 machine and personal computer. The Keithley 6487 provided electric source and measured output current, while the personal computer recorded measurement data.

\section{Results and Discussion}

Figure 2 shows the SEM images of $\mathrm{ZnO}$ nanoparticles annealed at $400^{\circ} \mathrm{C}, 600^{\circ} \mathrm{C}$, and $800^{\circ} \mathrm{C}$. We can observe that the size of $\mathrm{ZnO}$ nanoparticles became larger with higher annealing temperature. With the high-temperature annealing, the reaction to UV irradiation was enhanced. Figure 3 shows the XRD spectrum of $\mathrm{Al}_{2} \mathrm{O}_{3}$ substrate and $\mathrm{ZnO}$ nanoparticle on $\mathrm{Al}_{2} \mathrm{O}_{3}$ substrate. It is found that all the diffraction peaks of $\mathrm{ZnO}$ nanoparticle and $\mathrm{Al}_{2} \mathrm{O}_{3}$ could be indexed to the wurtzite structure $\mathrm{ZnO}$ and $\mathrm{Al}_{2} \mathrm{O}_{3}$ according to the standard JCPDS (no. 897716 and no. 751526) card. Figure 4 shows the current-time curves of $\mathrm{ZnO}$ nanoparticle film when UV light is on and off. We could see that the UV light can enhance the film's sensitivity, and the film shows good reversibility. The dynamic response was stable and reproducible with good on/off current ration.

For ethanol gas sensing, it is known that oxygen sorption plays an important role in electrical transport properties of $\mathrm{ZnO}$ nanoparticles. It is also known that oxygen ionosorption removes conduction electrons and thus lowers the conductance of $\mathrm{ZnO}$. Hence, the sensing mechanism of $\mathrm{ZnO}$ on ethanol gas may be described as follows. First, reactive oxygen species such as $\mathrm{O}_{2}{ }^{-}, \mathrm{O}^{2-}$, and $\mathrm{O}^{-}$are adsorbed on $\mathrm{ZnO}$ surface at elevated temperatures. It should be noted that the chemisorbed oxygen species depend strongly on temperature. At low temperatures, $\mathrm{O}_{2}{ }^{-}$is commonly chemisorbed. At high temperatures, however, $\mathrm{O}^{-}$and $\mathrm{O}^{2-}$ are commonly chemisorbed, while $\mathrm{O}_{2}{ }^{-}$disappear rapidly [23]. The reaction kinematics can be described as follows [24]:

$$
\begin{gathered}
\mathrm{O}_{2} \text { (gas) } \longleftrightarrow \mathrm{O}_{2} \text { (absorbed) } \\
\mathrm{O}_{2}(\text { absorbed })+\mathrm{e}^{-} \longleftrightarrow \mathrm{O}_{2}{ }^{-} \\
\mathrm{O}_{2}{ }^{-}+\mathrm{e}^{-} \longleftrightarrow 2 \mathrm{O}^{-}
\end{gathered}
$$

Thus, the conductance of $\mathrm{ZnO}$ nanoparticles will increase as ethanol gas is introduced into the test chamber due to the exchange of electrons between ionosorbed species and $\mathrm{ZnO}$ nanoparticles. The reaction between ethanol and ionic oxygen species can be described by [25]

$$
\mathrm{CH}_{3} \mathrm{CH}_{2} \mathrm{OH}_{\mathrm{ads}}+6 \mathrm{O}^{-} \text {ads } \longrightarrow 2 \mathrm{CO}_{2}+3 \mathrm{H}_{2} \mathrm{O}+6 \mathrm{e}^{-} \text {. }
$$

Figure 5 shows the sensitivity of $\mathrm{ZnO}$ nanoparticle with annealing temperature at $400^{\circ} \mathrm{C}, 600^{\circ} \mathrm{C}$, and $800^{\circ} \mathrm{C}$ in the environment of ethanol $200 \mathrm{ppm}$. We can observe that the $\mathrm{ZnO}$ nanoparticle film annealing at $800^{\circ} \mathrm{C}$ has the highest sensitivity. We know that several kinds of defect $\left(\mathrm{V}_{\mathrm{Zn}}, \mathrm{O}_{\mathrm{i}}\right.$, and $\mathrm{O}_{\mathrm{Zn}}$ ) of $\mathrm{ZnO}$ can be formed when annealing in oxygen atmosphere at high temperature. Therefore, the highest sensitivity can be attributed to the defects of $\mathrm{ZnO}$ nanoparticle film annealing at $800^{\circ} \mathrm{C}$ much more than other annealing 


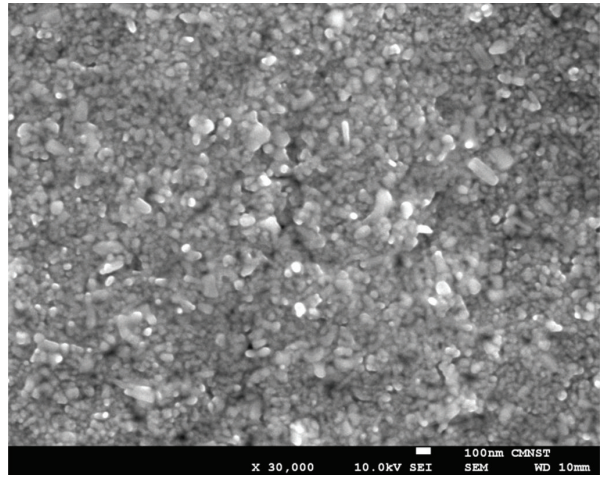

(a)

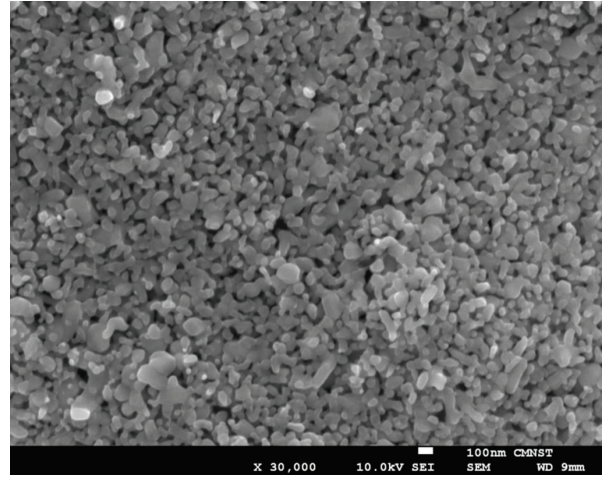

(b)

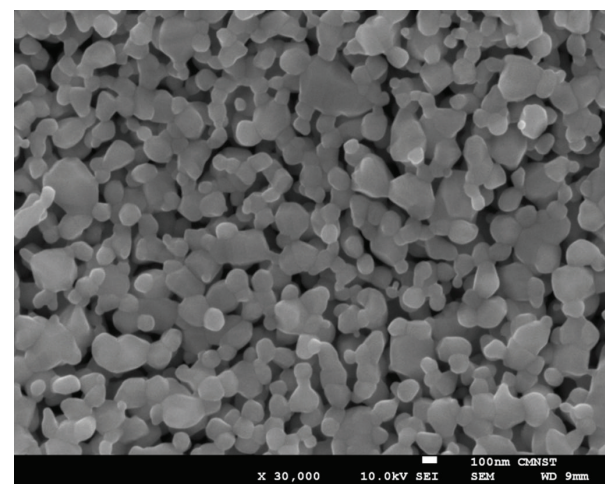

(c)

FIgure 2: The SEM image tilt at $45^{\circ}$ SEM images of the $\mathrm{ZnO}$ nanoparticle on $\mathrm{Al}_{2} \mathrm{O}_{3}$ substrate after annealing at (a) $400^{\circ} \mathrm{C}$, (b) $600^{\circ} \mathrm{C}$, and (c) $800^{\circ} \mathrm{C}$ for 1 hour.

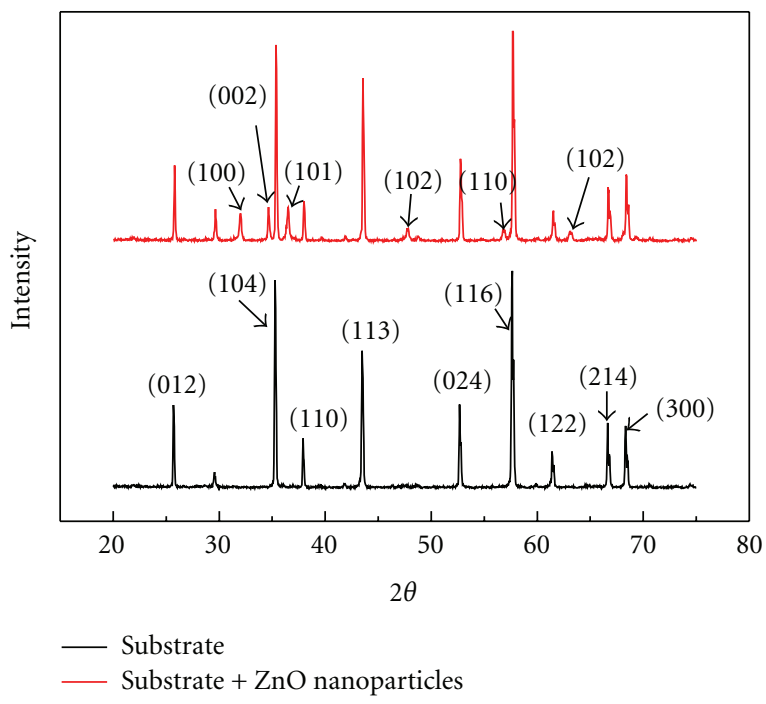

FIgURE 3: The XRD spectrum of $\mathrm{ZnO}$ nanoparticle on $\mathrm{Al}_{2} \mathrm{O}_{3}$ substrate.

temperatures. Figure 6 shows room temperature PL spectra measured from the nanoparticle on $\mathrm{Al}_{2} \mathrm{O}_{3}$ substrate with various annealing temperatures. Deep-level emissions (i.e., green-yellow bands) are also observed as the long tails shown in Figure 6. It has been suggested that deep-level emissions

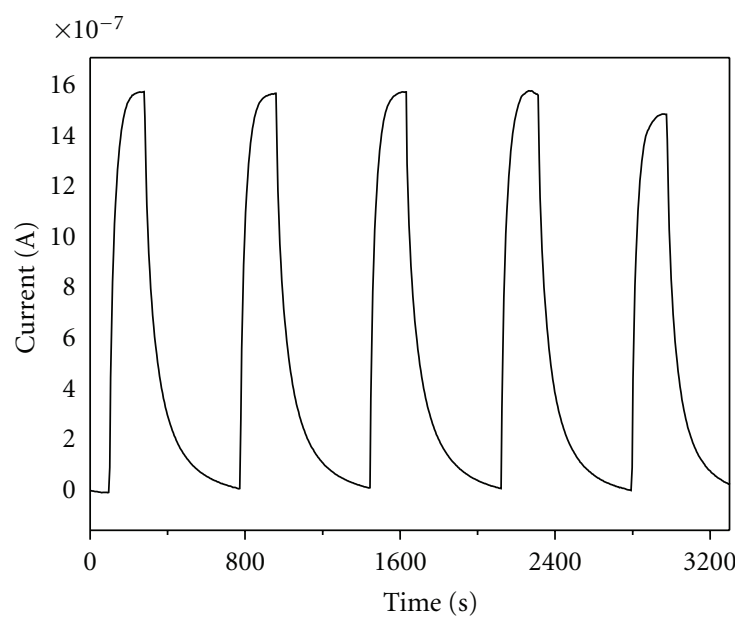

FIgure 4: Current flowing through the $\mathrm{ZnO}$ nanoparticle film as the light is turned on and off at room temperature.

are related to the singly ionized oxygen vacancy in $\mathrm{ZnO}$. Previously, it has been shown that defect-related emissions are originated from radiative transitions between oxygenvacancy-related shallow donors. Figure 7 is the sensitivity of the $\mathrm{ZnO}$ nanoparticle film annealing at $800^{\circ} \mathrm{C}$ with different concentrations in ethanol. 


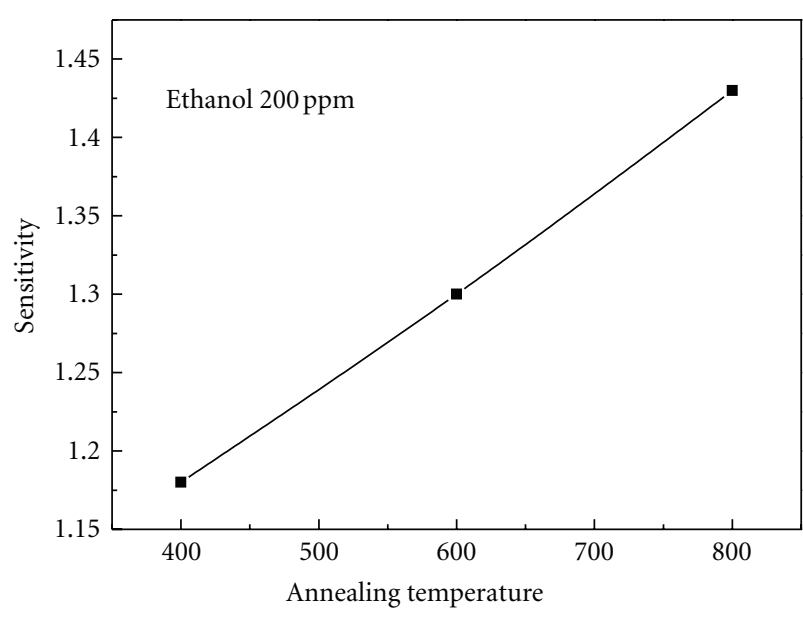

Figure 5: The sensitivity of the $\mathrm{ZnO}$ nanoparticle with several annealing temperatures in ethanol $200 \mathrm{ppm}$.

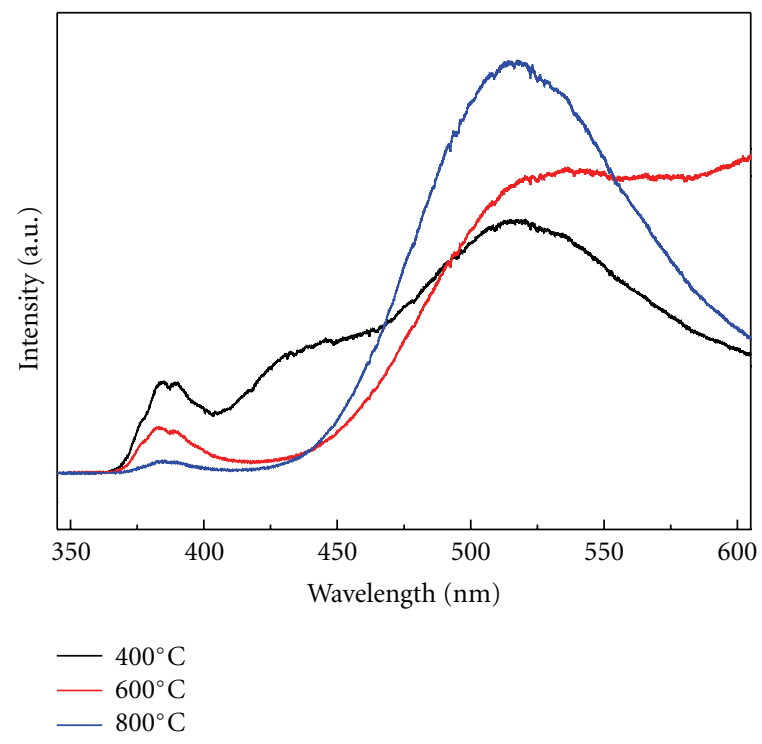

Figure 6: Room temperature PL spectra measured from the nanoparticle on $\mathrm{Al}_{2} \mathrm{O}_{3}$ substrate with various annealing temperatures.

To quantify the sensor performance, we define the response of our sensor as $\left(R_{\mathrm{gas}} / R_{\mathrm{ill}}\right)$. $R_{\mathrm{gas}}$ is sensor's resistance after reaching a steady state when sensing the reducing gas, and $R_{\mathrm{ill}}$ is sensor's resistance with UV light illumination. The highest sensitivity is about 1.45 at $200 \mathrm{ppm}$ in ethanol. In other words, the sensor response increased with an increase of ethanol gas concentration. From the data plotted in Figure 7 , it was found that the corresponding response time was $62 \mathrm{sec}$, while that for recover time was $71 \mathrm{sec}$ at $200 \mathrm{ppm}$. It should be noted that the response time observed in this study was much smaller than that reported by Gong et al. [26]. It was also found that the measured device resistivity responded rapidly as we injected ethanol gas into the chamber and pumped them away. Such a result indicates that the response speed of the fabricated sensor is also good.

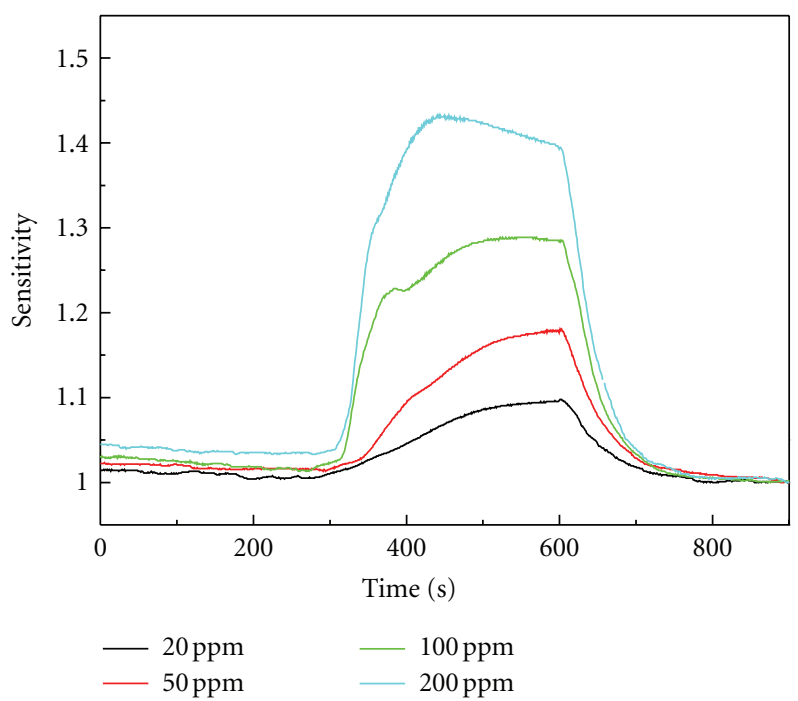

FIGURE 7: The sensitivity of the $\mathrm{ZnO}$ nanoparticle film annealing at $800^{\circ} \mathrm{C}$ with several concentrations in ethanol.

\section{Conclusion}

In this study, the $\mathrm{ZnO}$ nanoparticles films were fabricated by spin coating. The I-V characteristics and ethanol gas sensing properties of the $\mathrm{ZnO}$ nanoparticle sensors with UV light illumination were investigated at RT. It could be observed that the $\mathrm{ZnO}$ nanoparticle film annealing at $800^{\circ} \mathrm{C}$ has the highest sensitivity. The highest sensitivity was about 1.45 at $200 \mathrm{ppm}$ in ethanol. The results show that the $\mathrm{ZnO}$ nanoparticle sensors have immediate response, high sensitivity, and good reproducibility for ethanol gas detection. These $\mathrm{ZnO}$ nanoparticle sensors junctions have potential application as RT ethanol gas sensors.

\section{Acknowledgments}

The authors would like to thank the National Science Council and Bureau of Energy, Ministry of Economic Affairs of Taiwan, R.O.C. for the financial support under Contract No. 100-2221-E-006-168 and 101-D0204-6 and the LED Lighting Research Center of NCKU for the assistance of device characterization. This work was also supported in part by the Center for Frontier Materials and Micro/Nano Science and Technology, the National Cheng Kung University, Taiwan. This work was also supported in part by the Advanced Optoelectronic Technology Center, the National Cheng Kung University, under projects from the Ministry of Education.

\section{References}

[1] Y. Huang, X. Duan, Q. Wei, and C. M. Lieber, "Directed assembly of one-dimensional nanostructures into functional networks," Science, vol. 291, no. 5504, pp. 630-633, 2001.

[2] W. Lu and C. M. Lieber, "Nanoelectronics from the bottom up," Nature Materials, vol. 6, no. 11, pp. 841-850, 2007.

[3] M. H. Huang, S. Mao, H. Feick et al., "Room-temperature ultraviolet nanowire nanolasers," Science, vol. 292, no. 5523, pp. 1897-1899, 2001. 
[4] F. Qian, Y. Li, S. Gradečak, D. Wang, C. J. Barrelet, and C. M. Lieber, "Gallium nitride-based nanowire radial heterostructures for nanophotonics," Nano Letters, vol. 4, no. 10, pp. 1975-1979, 2004.

[5] P. V. Radovanovic, C. J. Barrelet, S. Gradečak, F. Qian, and C. M. Lieber, "General synthesis of manganese-doped II-VI and III-V semiconductor nanowires," Nano Letters, vol. 5, no. 7, pp. 1407-1411, 2005.

[6] Y. Cui, Z. Zhong, D. Wang, W. U. Wang, and C. M. Lieber, "High performance silicon nanowire field effect transistors," Nano Letters, vol. 3, no. 2, pp. 149-152, 2003.

[7] M. Law, L. E. Greene, J. C. Johnson, R. Saykally, and P. Yang, "Nanowire dye-sensitized solar cells," Nature Materials, vol. 4, no. 6, pp. 455-459, 2005.

[8] S. A. Mcdonald, G. Konstantatos, S. Zhang et al., "Solutionprocessed $\mathrm{PbS}$ quantum dot infrared photodetectors and photovoltaics," Nature Materials, vol. 4, no. 2, pp. 138-142, 2005.

[9] I. L. Medintz, H. T. Uyeda, E. R. Goldman, and H. Mattoussi, "Quantum dot bioconjugates for imaging, labelling and sensing," Nature Materials, vol. 4, no. 6, pp. 435-446, 2005.

[10] W. K. Hong, J. I. Sohn, D. K. Hwang et al., "Tunable electronic transport characteristics of surface-architecture-controlled ZnO nanowire field effect transistors," Nano Letters, vol. 8, no. 3, pp. 950-956, 2008.

[11] J. B. Baxter and E. S. Aydil, "Nanowire-based dye-sensitized solar cells," Applied Physics Letters, vol. 86, no. 5, Article ID 053114, pp. 1-3, 2005.

[12] J. Chen, Y. Zhang, B. J. Skromme, K. Akimoto, and S. J. Pachuta, "Properties of the shallow O-related acceptor level in ZnSe," Journal of Applied Physics, vol. 78, no. 8, pp. 5109-5119, 1995.

[13] H. Kato, M. Sano, K. Miyamoto, and T. Yao, "Homoepitaxial growth of high-quality $\mathrm{Zn}$-polar $\mathrm{ZnO}$ films by plasma-assisted molecular beam epitaxy," Japanese Journal of Applied Physics Part 2, vol. 42, no. 8B, pp. L1002-L1005, 2003.

[14] T. Sergiu, T. S. Shishiyanu, and O. I. Lupan, "Sensing characteristics of tin-doped $\mathrm{ZnO}$ thin films as $\mathrm{NO}_{2}$ gas sensor," Sensors and Actuators B, vol. 107, no. 1, pp. 379-386, 2005.

[15] N. Koshizaki and T. Oyama, "Sensing characteristics of ZnObased $\mathrm{NO}_{x}$ sensor," Sensors and Actuators B, vol. 66, no. 1, pp. 119-121, 2000.

[16] L. C. Tien, P. W. Sadik, D. P. Norton et al., "Hydrogen sensing at room temperature with $\mathrm{Pt}$-coated $\mathrm{ZnO}$ thin films and nanorods," Applied Physics Letters, vol. 87, no. 22, Article ID 222106, pp. 1-3, 2005.

[17] M. S. Wagh, G. H. Jain, D. R. Patil, S. A. Patil, and L. A. Patil, "Modified zinc oxide thick film resistors as $\mathrm{NH}_{3}$ gas sensor," Sensors and Actuators B, vol. 115, no. 1, pp. 128-133, 2006.

[18] J. Wöllenstein, J. A. Plaza, C. Cané, Y. Min, H. Böttner, and H. L. Tuller, "A novel single chip thin film metal oxide array," Sensors and Actuators B, vol. 93, no. 1-3, pp. 350-355, 2003.

[19] S. Mridha and D. Basak, "Investigation of a $\mathrm{p}-\mathrm{CuO} / \mathrm{n}-\mathrm{ZnO}$ thin film heterojunction for $\mathrm{H}_{2}$ gas-sensor applications," Semiconductor Science and Technology, vol. 21, no. 7, article 017, pp. 928-932, 2006.

[20] G. G. Huang, C. T. Wang, H. T. Tang, Y. S. Huang, and J. Yang, " $\mathrm{ZnO}$ nanoparticle-modified infrared internal reflection elements for selective detection of volatile organic compounds," Analytical Chemistry, vol. 78, no. 7, pp. 2397-2404, 2006.

[21] Y. Sun, N. George Ndifor-Angwafor, D. Jason Riley, and M. N. R. Ashfold, "Synthesis and photoluminescence of ultrathin $\mathrm{ZnO}$ nanowire/nanotube arrays formed by hydrothermal growth," Chemical Physics Letters, vol. 431, no. 4-6, pp. 352357, 2006.

[22] P. Mitra, A. P. Chatterjee, and H. S. Maiti, " $\mathrm{ZnO}$ thin film sensor," Materials Letters, vol. 35, no. 1-2, pp. 33-38, 1998.

[23] D. Kohl, "The role of noble metals in the chemistry of solidstate gas sensors," Sensors and Actuators B, vol. 1, no. 1-6, pp. 158-165, 1990.

[24] P. P. Sahay, "Zinc oxide thin film gas sensor for detection of acetone," Journal of Materials Science, vol. 40, no. 16, pp. 43834385, 2005.

[25] T. Gao and T. H. Wang, "Synthesis and properties of multipodshaped $\mathrm{ZnO}$ nanorods for gas-sensor applications," Applied Physics A, vol. 80, no. 7, pp. 1451-1454, 2005.

[26] J. Gong, Y. Li, X. Chai, Z. Hu, and Y. Deng, "UV-light-activated $\mathrm{ZnO}$ fibers for organic gas sensing at room temperature," Journal of Physical Chemistry C, vol. 114, no. 2, pp. 1293-1298, 2010. 

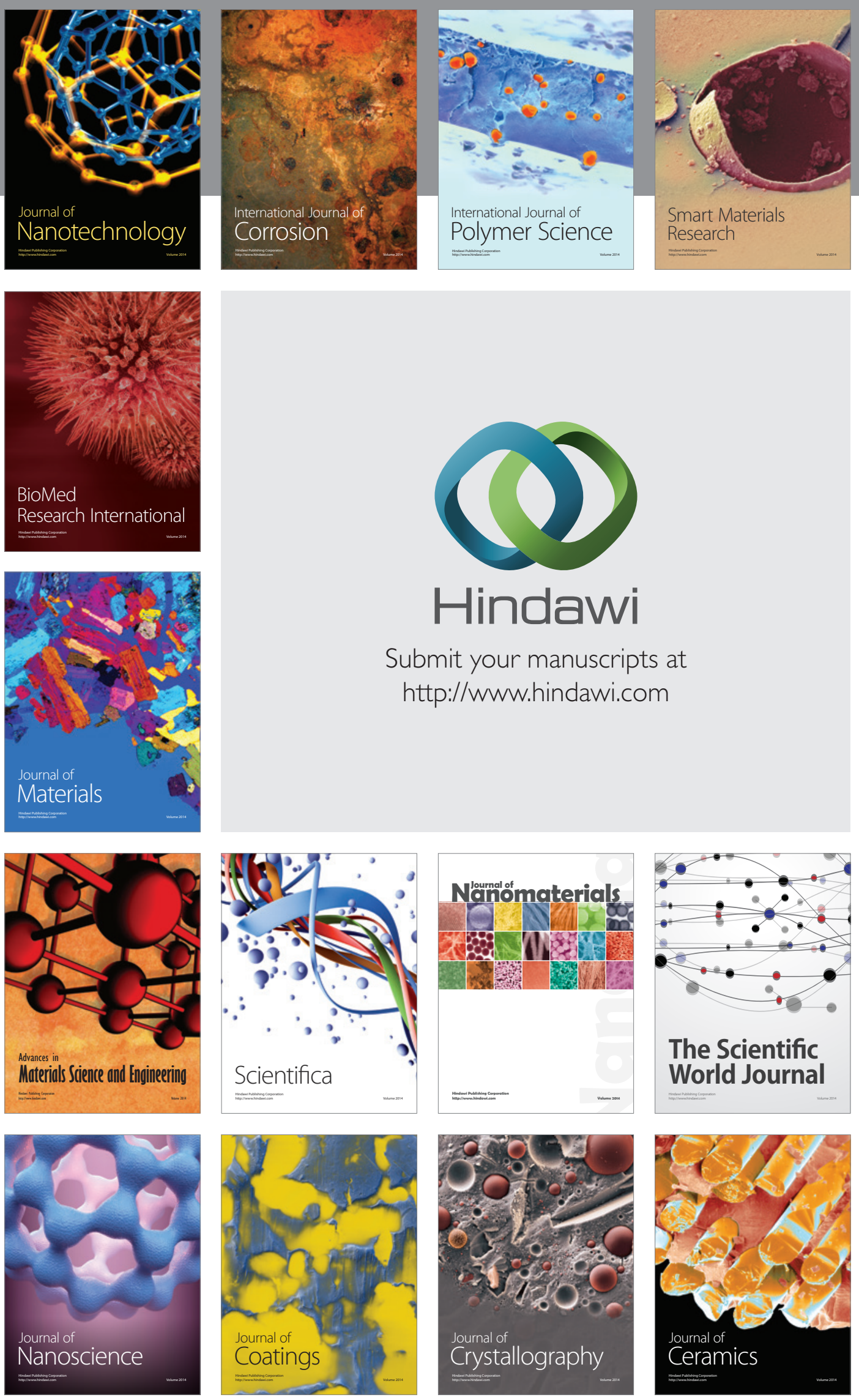

The Scientific World Journal

Submit your manuscripts at

http://www.hindawi.com

\section{World Journal}

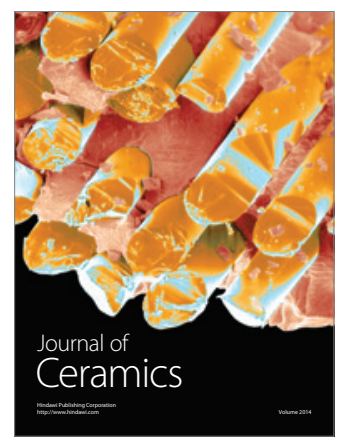

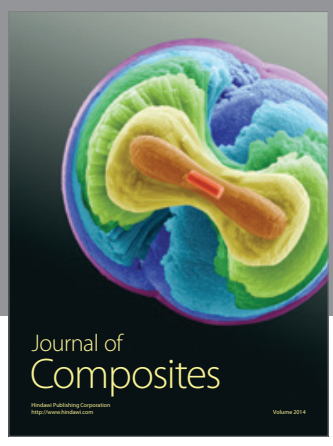
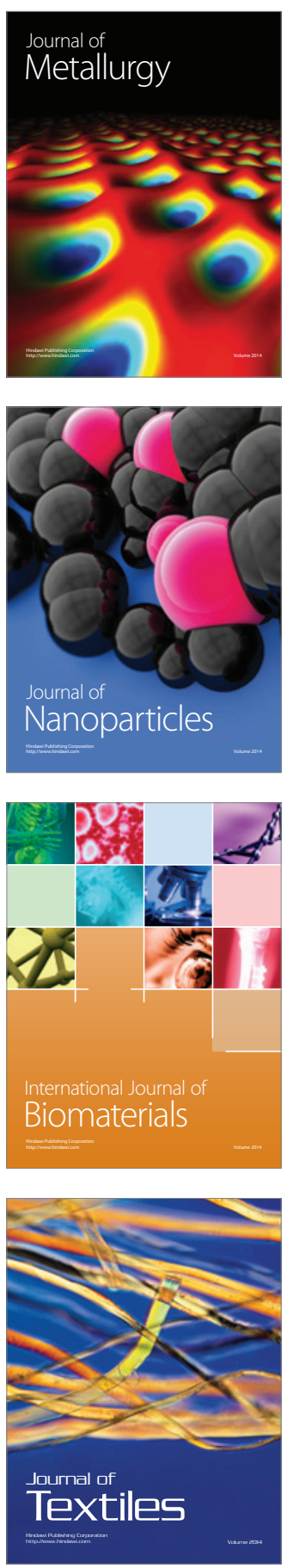